\title{
Kadar Glukosa Darah Puasa Akseptor Kontrasepsi Suntik dan AKDR
}

\author{
Siti Cholifah', ${ }^{1}$ Paramitha Amelia Kusumawardani², Miftahul Muslih ${ }^{3}$, Siti Nur Azizah ${ }^{4}$ \\ 1. Prodi Pendidikan Profesi Bidan FIKES Universitas Muhammadiyah Sidoarjo, \\ email: siticholifah@umsida.ac.id
}

2. Prodi Teknologi Laboratorium Medik FIKES Universitas Muhammadiyah Sidoarjo

\begin{abstract}
Abstrak. Penggunaan kontrasepsi untuk mengatur jarak kehamilan dan mengakhiri kesuburan, Kontrasepsi hormonal yang banyak diminati yaitu kontrasepsi suntik. Sedangkan AKDR merupakan alat kontrasepsi yang mempunyai efek jangka panjang dan angka penggunaanya lebih kecil dibandingkan suntik. Kontrasepsi suntik dianggap efektif, praktis, tanpa perlu pemeriksaan dalam, namun mempunyai beberapa efek samping, salah satunya yaitu mempengaruhi peningkatan glukosa darah. Tujuan penelitian mengetahui perbedaan kadar glukosa darah pada akseptor kontrasepsi suntik progestin, kombinasi dan AKDR. Desain penelitian observasional menggunakan pendekatan cross sectional. Sampel penelitian akseptor kontasepsi suntik progestin (DMPA), suntik kombinasi dan AKDR yang memenuhi kriteria inklusi berjumlah 70 sampel, Hasil penelitian menunjukkan rerata kadar glukosa darah pada akseptor suntik progestin mean \pm SD $110 . .36$ \pm 18.610 , akseptor suntik kombinasi mean \pm SD $96.36 \pm 16.867$, dan akseptor AKDR mean \pm SD $92.15 \pm 14.572$, analisis dengan uji one way anova dengan menggunakan $\alpha=0,05$. Hasil penelitian terdapat perbedaan kadar glukosa darah puasa pada akseptor suntik progestin, akeptor suntik kombinasi dan AKDR dengan nilai $\mathrm{P}=0.001<\alpha$ 0.05. Simpulan penelitian menunjukkan terdapat perbedaan kadar glukosa darah akseptor suntik progestin, kombinasi dan AKDR. Saran bagi pemberi pelayanan kontrasepsi untuk melakukan pengecekkan kadar glukosa darah akseptor suntik secara berkala, sehingga bisa dideteksi jika kadar glukosa darah meningkat.
\end{abstract}

Kata kunci : kontrasepsi, suntik, progestin, kombinasi, AKDR, glukosa darah.

Fasting Blood Glucose Levels For Injection Contraceptive Acceptors And IUD Abstract. The use of contraception to regulate distance pregnancy and end fertility, hormonal contraception that great demand namely injection contraception. Whereas IUD is contraceptive device that has a longterm effect and rate of use is smaller than injection. Injectable contraception is considered effective, practical, without the need for a deep examination, but has several side effects, one of which is that affects an increase in blood glucose. The purpose of this study was to determine differences in blood glucose levels in progestin injection, combined and IUD injection contraception acceptors. Observational research design using a cross sectional approach. The sample of progestin injection contraception acceptor (DMPA), combination injection and IUD that met the inclusion criteria totaled 70 samples. The results showed the average blood glucose level in the progestin injection syringe mean $+S D 110 . .36+18.610$, the combined injection acceptor mean $+S D 96.36+16,867$, and IUD mean acceptor SD $92.15+14.572$, analysis by one way $A N O V A$ test using $\alpha=0.05$. The results of the study showed differences in fasting blood glucose levels in progestin injection acceptors, combined injection acceptors and IUDs with a P value of $0.001<\alpha$ 0.05. The conclusions of the study showed that there were differences in blood glucose levels of progestininjecting injectors, combinations and the IUD. Suggestions for providers of contraception to check blood glucose levels of injector acceptors regularly, so they can be detected if the blood glucose level rises.

Keywords : contraception, injection, progestin, combination, IUD, blood glucose. 


\section{Pendahuluan}

Penduduk Indonesia di tahun 2018 jumlahnya mencapai 276 juta, Indonesia termasuk dalam negara dengan jumlah penduduk terbesar ke empat didunia. Propinsi Jawa Timur mempunyai jumlah penduduk 39.292.972 merupakan propinsi dengan jumlah penduduk terbesar kedua di Indonesia setelah propinsi jawa barat (Dinas Kesehatan Jawa Timur, 2017). Upaya pemerintah untuk mengendalikan jumlah penduduk melalui program keluarga berencana salah satunya adalah dengan pemakaian alat kontrasepsi yang bertujuan untuk membatasi dan mengatur jarak kelahiran serta mengakhiri kesuburan agar terwujud keluarga sehat dan sejahtera (JNPKKR/POGI, BKKBN, 2014). Jenis kontrasepsi bermacam-macam ada metode hormonal dan non hormonal, yang termasuk metode hormonal yaitu suntik, pil, dan implant sedangkan non hormonal yaitu Alat kontrasepsi Dalam Rahim (AKDR), kondom dan kontrasepsi mantap (Glasier dan Gebbie, 2016). Berdasarkan data Riskesda (2018) Pemakaian kontrasepsi di Indonesia adalah kontrasepsi suntik sebesar $62,77 \%$, pil $17,24 \%$, kondom $1,22 \%$, IUD 7,15\%, MOW 2,78, implant $6,99, \%$ dan MOP 0,53\%. Pemakaian kontrasepsi di Jawa Timur suntik 58,5\%, Implan 9,2 \% dan AKDR 9,5\% (Kolifah, Nugroho dan Hidayah, 2013). Sedangkan penggunaan kontrasepsi pada akseptor aktif di kabupaten Sidoarjo yaitu suntik $61.6 \%$ dari 287.8111 akseptor, dan AKDR sebanyak 7,2\% (Dinas Kesehatan Jawa Timur, 2017). Kontrasepsi suntik mengandung hormon estrogen dan progesteron, serta mengandung hormon progestin saja. Pemakaian kontrasepsi suntik mempunyai beberapa efek samping antara lain mengganggu pola haid bisa berupa aminorhea, spotting, perubahan berat badan berat badan mengalami peningkatan bahkan mempunyai risiko 2 kali lipat mengalami obesitas pada pemakaian $\geq 2$ tahun, keputihan, sakit kepala, rambut rontok (Sari, F \& Pramestiyani, 2017). Selain itu kontrasepsi suntik bisa menyebabkan efek samping peningkatan kadar glukosa darah (Fafelia R.M., Joserizal S, 2019). Hormon progesteron yang terdapat dalam kontrasepsi suntik mempunyai sifat antiinsulin yang mengakibatkan sel-sel menjadi kurang sensitif terhadap insulin, hal ini bisa membuat resistensi insulin dalam tubuh yang akan mempengaruhi metabolisme gula sehingga mengakibatkan peningkatan kadar gula darah (Manuel, 2014). Kadar glukosa darah yang meningkat dalam darah bisa menjadi tanda gejala dari penyakit diabetes mellitus (Fox, 2010). Kadar glukosa darah puasa yang normal adalah kurang dari 126 mg/dl sedangkan untuk kadar glukosa darah acak adalah yaitu kurang dari 200 mg/dl (Fox, 2010). Selain efek dari kontrasepsi hormonal, ada beberapa faktor yang menyebabkan peningkatan kadar glukosa darah yaitu usia lebih 40 tahun, obesitas, asupan makanan, stres, olah raga dan mempunyai riwayat penyakit Diabetes mellitus (Barenson, AB, Van de Berg P, 2011).

Data hasil studi pendahuluan yang dilakukan di PMB Lusi wahyuni Sidoarjo, penggunaan kontrasepsi pada tahun 2019 dari peserta KB aktif yang berkunjung terdapat kontrasepsi 1.800 orang $(91,5 \%)$ akseptor kontrasepsi suntik dari 1.967 orang Pemakaian kontrasepsi suntik sangat tinggi dibandingkan dengan kontrasepsi hormonal lain implant dan pil. Tujuan penelitian ini untuk mengetahui 
Kadar glukosa darah pada akseptor kontrasepsi suntik dan AKDR.

\section{Metode}

Jenis penelitian yang digunakan adalah penelitian kuantitatif. Desain penelitian observasional, pendekatan cross sectioanal. Populasi pada penelitian ini yakni seluruh akseptor KB yang melakukan kunjungan ulang di PMB Sidoarjo. Sampel penelitian akseptor KB kunjungan ulang yang memenuhi kriteria inklusi bersedia diteliti, tidak ada riwayat penyakit DM, usia kurang 40 tahun, Berpuasa minimal 6-8 jam berjumlah 70 akseptor (25 akseptor suntik progestin, 25 akseptor suntik kombinasi dan 20 akseptor AKDR menggunakan consecutive sampling.. Analisis data menggunakan one way anova dengan interval kepercayaan 95\% dan tingkat kemaknaan $\mathrm{P}<0,05$.

Penelitian ini melibatkan 70 akseptor yang dijadikan subyek penelitian dan memenuhi kriteria inklusi. Pengambilan data dilakukan mulai tanggal 1 Februari 2020 sampai dengan 15 Maret 2020 di PMB Sidoarjo.

\section{Hasil penelitian.}

Data dikelompokkan dalam 2 kelompok yaitu data umum meliputi karakterisik responden dan data khusus mengenai kadar glukosa darah puasa akseptor kontrasepsi suntik, dan AKDR. Data tersebut disajikan dalam tabel sebagai berikut :

\begin{tabular}{|c|c|c|c|c|c|c|}
\hline \multirow{2}{*}{$\begin{array}{c}\text { Karakte } \\
\text { ristik }\end{array}$} & \multicolumn{2}{|c|}{$\begin{array}{c}\text { Suntik } \\
\text { Progestin }\end{array}$} & \multicolumn{2}{|c|}{$\begin{array}{c}\text { Suntik } \\
\text { Kombinasi }\end{array}$} & \multicolumn{2}{|c|}{ AKDR } \\
\hline & Mean & SD & Mean & SD & Mean & SD \\
\hline Paritas & 1.92 & 0.64 & 2.16 & 0.68 & 2.20 & 0.69 \\
\hline $\begin{array}{l}\text { Lama } \\
\text { Pemakai } \\
\text { an }\end{array}$ & 5.84 & 3.06 & 6.06 & 3.35 & 5.12 & 2.11 \\
\hline
\end{tabular}

Tabel 5.1 rerata paritas dari ketiga kelompok tidak jauh berbeda, sedangkan rerata lama pemakaian lebih tinggi pada suntik kombinasi dibandingkan suntik progestin dan AKDR

Data khusus penelitian kadar glukosa darah pada akseptor kontrasepsi suntik progestin, suntik kombinasi dan Alat Kontrasepsi Dalam Rahim (AKDR) disajikan pada tabel berikut ini :

Tabel 5.2 Perbedaan Kadar glukosa darah puasa pada Akseptor suntik progestin, Suntik kombinasi dan AKDR

\begin{tabular}{|c|c|c|}
\hline \multirow[t]{2}{*}{ Kontrasepsi } & Kadar glukosa & \multirow[t]{2}{*}{$P$} \\
\hline & $\begin{array}{l}\text { darah puasa } \\
\text { Rerata } \pm \mathrm{SD} \\
(\mathrm{mg} / \mathrm{dl}\end{array}$ & \\
\hline Suntik Progestin & $\begin{array}{l}110.36 \\
18.610\end{array}$ & \\
\hline Suntik Kombinasi & $\begin{array}{r}96.36 \\
16.867\end{array}$ & 0,001 \\
\hline $\begin{array}{lr}\text { Alat } & \text { kontrasepsi } \\
\text { Dalam } & \text { Rahim } \\
\text { (AKDR) } & \end{array}$ & $\begin{array}{r}92.15 \\
14.572\end{array}$ & \\
\hline
\end{tabular}

Berdasarkan tabel 5.2 menunjukkan rerata kadar glukosa darah pada akseptor suntik progestin Mean \pm SD 110..36 \pm 18.610 , Akseptor suntik kombinasi Mean \pm SD $96.36 \pm 16.867$, dan akseptor AKDR Mean \pm SD $92.15 \pm$ 14.572. Hasil uji one way anova $\mathrm{P}=0,001<0,05$ berarti terdapat pebedaan yang bermakna kadar glukosa darah puasa pada akseptor. 
Tabel. 5.4 hasil analisis Post -hoc LSD

\begin{tabular}{lcccc} 
& Perbedaan & \multicolumn{2}{c}{ IK 95\% } & \multirow{2}{*}{$P$} \\
\cline { 3 - 4 } & rerata & Min & Maks & \\
\cline { 3 - 4 } & 14.000 & 4.45 & 23.55 & 0.005 \\
$\begin{array}{l}\text { Progestin } \\
\text { vs }\end{array}$ & & & & \\
$\begin{array}{l}\text { kombinasi } \\
\begin{array}{l}\text { Progestin } \\
\text { vs AKDR }\end{array}\end{array}$ & 18.210 & 8.08 & 28.34 & 0.001 \\
$\begin{array}{l}\text { Kombinasi } \\
\text { vs AKDR }\end{array}$ & 4.20 & -5.72 & 14.34 & 0.410 \\
\hline
\end{tabular}

Uji post-hoc LSD

Berdasarkan tabel 5.3 hasil analisis Post hoc LSD menunjukkan bahwa terdapat perbedaan bermakna kadar gula darah puasa pada akseptor suntik progestin dengan akseptor suntik kombinasi $P$ value $=0,005, \quad$ terdapat perbedaan bermakna kadar glukosa darah puasa pada akseptor suntik progestin dengan akseptor Alat Kontrasepsi Dalam Rahim (AKDR) $P$ value $=0,001$. Tidak ada Perbedaan yang bermakna akseptor suntik kombinasi dengan akseptor Alat Kontrasepsi Dalam Rahim (AKDR) P value $=0,410$.

\section{Pembahasan.}

Rerata kadar glukosa darah puasa pada pengguna kontrasepsi progestin lebih tinggi dari akseptor suntik kombinasi dan AKDR, hasil uji one way anova menunjukkan terdapat perbedaan yang bermakna kadar gula darah puasa antara akseptor kontrasepsi progestin, suntik kombinasi dan akseptor Alat Kontrasepsi Dalam Rahim (AKDR). Hal ini menunjukkan bahwa kontrasepsi suntik progestin yang meliliki kandungan sintetis hormon progesteron saja kadar glukosa darah puasa lebih tinggi dari kontrasepsi suntik kombinasi yang berisi sintetis hormon progesteron dan estrogen atau kadar glukosa darah puasa pada akseptor kontrasepsi AKDR yang tidak terdapat kandungan hormon progesteron maupun estrogen rerata kadar glukosa darah puasa paling rendah dibandingkan dengan akseptor suntik (Meysetri, Serudji dan Agus, 2019).

Hasil penelitian ini didukung oleh penelitian Barenson et al (2011) bahwa kadar glukosa akseptor kontrasepsi suntik progestin mengalami peningkatan lebih tinggi dari kontrasepsi hormon pil kombinasi (Barenson, AB, Van de Berg P, 2011). Penelitian lain yang menunjang dilakukan oleh Sari (Sari, F \& Pramestiyani, 2017), penggunaan kontrasepsi yang mengandung progesteron mempunyai rerata kadar glukosa lebih tinggi dari pada kontrasepsi hormonal yang kombinasi. ${ }^{14}$ Selain itu penelitian yang dilakukan Rahma (Siti Rahma, 2019) ada hubungan yang signifikan antara penggunaan kontrasepsi hormonal suntik dengan peningkatan kadar gula darah.

Peningkatan kadar progesteron menyebabkan Peningkatan kadar kortisol dalam sirkulasi darah sehingga mempengaruhi proses metabolisme karbohidrat (glukosa) sehingga glukosa dalam darah meningkat. Selain itu progesteron menyebabkan kepekaan selsel tubuh terhadap insulin berkurang sehingga membutuhkan banyak insulin dalam metabolisme glukosa, kondisi ini bisa menyebabkan kadar glukosa dalam darah meningkat (Siti Rahma, 2019).

Rerata suntik kombinasi lebih rendah dari pada suntik progestin dan lebih tinggi dari AKDR. Suntik kombinasi berisi hormon progesteron dan estrogen. Kontrasepsi yang mempunyai kandungan estrogen tidak mempunyai dampak yang merugikan terhadap metabolism glukosa (Manuel, 2014). Hormon progesteron dan estrogen sebagai salah satu faktor yang dapat 
mempengaruhi kadar glukosa darah dalam tubuh seorang wanita. Fluktuasi naik turunnya hormon tersebut dapat mempengaruhi kondisi kadar glukosa dalam tubuh. Ketika kadar hormon estrogen naik sel-sel tubuh menjadi lebih sensitife terhadap insulin sehingga membatu penyerapan glukosa (Fox, 2010). Ketika dalam tubuh terjadi penurunan kadar estrogen dan terjadi peningkatan kadar hormon progesteron maka sel-sel dalam tubuh menjadi lebih resisten terhadap insulin, sehingga dibutuhkan lebih banyak insulin supaya bisa membatu sel-sel menyerap glukosa dari darah, resistensi terhadap insulin bisa menimbulkan kadar glukosa dalam darah meningkat (Manuel, 2014)

Simpulan.

Simpulan penelitian ini adalah rerata kadar glukosa darah akseptor kontrasepsi suntik progestin lebih tinggi dibandingkan dengan akseptor suntik kombinasi dan Alat Kontrasepsi Dalam Rahim (AKDR). Terdapat perbedaan yang bermakna antara kadar glukosa darah puasa pada akseptor suntik progestin, akseptor kombinasi dan Akseptor Alat Kontrasepsi Dalam Rahim (AKDR).

\section{Ucapan Terima Kasih.}

Kepada Direktorat Riset dan Pengabdian Masyrakat (DRPM) Universitas Muhammadiyah Sidoarjo Kami ucapkan terimah kasih telah memberikan dana penelitian dan Pimpinan PMB sebagai tempat penelitian serta responden yang bersedia menjadi subyek dalam penelitian.

\section{Daftar Pustaka.}

Barenson, AB, Van de Berg P, W. K. (2011) "Effect of injectable and oral contaracepives on glucose and insulin level," Obstetric dan ginecology, hal. 4147.

Dinas Kesehatan Jawa Timur (2017). Jawa Timur.

Fafelia R.M., Joserizal S, dan M. A. (2019) "Perbedaan kadar glukosa darah pada akseptor suntik DMPA dengan pil kombinasi di puskesmas lubuk buaya Padang," Jurnal Kesehatan Andalasndalas, 8(2).

Fox, C. \& K. A. (2010) "Bersahabat dengan Diabetes Melitus Tipe 2," in. Jakarta: Penebar Plus.

Glasier, A. dan Gebbie, A. (2016) "Family Planning/Contraception," in International Encyclopedia of Public Health. doi: 10.1016/B978-0-12803678-5.00155-7.

JNPKKR/POGI, BKKBN, D. J. (2014)

Buku Panduan Praktis Pelayanan Kontrasepsi. Jakarta: Yayasan Bina Pustaka Sarwono.

Kolifah, Nugroho, B. dan Hidayah, M. (2013) "Faktor-Faktor Yang Mempengaruhi Tingginya Cakupan Akseptor Kb Memilih Metode Kb Suntik 3 Bulan Di Desa Cupak Kecamatan Ngusikan Kabupaten Jombang," Jurnal Metabolisme. doi: 10.16192/j.cnki.10032053.2018.02.014.

Manuel, E. C. \& A. A. A. (2014) "Effect of hormonal contraceptives on glicemic regulation.," Catholic medical Association, 8(3).

Meysetri, F. R., Serudji, J. dan Agus, M. (2019) "Perbedaan Kadar Glukosa Darah Puasa pada Akseptor Suntik Depo Medroksi Progesteron Asetat dengan Akseptor Pil Kombinasi di Puskesmas Lubuk Buaya Padang Tahun 2018," Jurnal Kesehatan Andalas. doi: 10.25077/jka.v8.i2.p227232.2019 .

Sari, F \& Pramestiyani, M. (2017) "Studi 
Jurnal Ilmiah Kesehatan Vol 14, No 1, Maret 2021, ISSN 1978-3167, E-ISSN 2580-135X

Komparasi Kadar glukosa darah Sewaktu pada akseptor Suntik Kombinasi dan Progestin di BPM Yosi Trihana Kalten Jawa Tengah," Jurnal Kesehatan "Samodra Ilmu," 8(1).

Siti Rahma, A. M. dan Y. Y. R. (2019) "Kadar gula darah pengguna kontrasepsi hormonal," Jambura Nursing Journal, 1(2). 